\title{
Thermal characterisation of the clay binder of heritage Sydney sandstones
}

\author{
K.H. Ip, B.H. Stuart*, P.S. Thomas and A.S. Ray \\ Department of Chemistry, Materials and Forensic Sciences, University of Technology, \\ Sydney, PO Box 123, Broadway NSW 2007, Australia \\ * Corresponding author
}

\begin{abstract}
Thermal analysis has been employed in a study of the degradation of heritage Sydney sandstone used in St Mary's Cathedral in Sydney, Australia. TGA and DSC have been used to characterise the clay components removed from weathered and unweathered sandstone. Two types of kaolin clays - kaolinite and its polymorph, dickite - have been identified. A higher amount of dickite present in the clay of weathered sandstone indicates that a kaoliniteto-dickite transformation occurs upon weathering. XRD hot stage analysis was also used to demonstrate the presence of a more thermally stable polymorph of the kaolinite.
\end{abstract}

Keywords: differential scanning calorimetry; sandstone; thermogravimetric analysis; weathering; $\mathrm{x}$-ray diffraction.

\section{Introduction}

A number of heritage buildings located in Sydney, Australia, are built from locally quarried sandstone and contribute a unique character to the city. After a period of exposure to the elements, sandstone buildings are showing signs of deterioration. In order to determine the appropriate conservation techniques for such buildings, it is important to gain an understanding of the method of degradation of the building stones.

A series of analytical techniques have been utilised in a study of the weathering of Sydney sandstones [1]. The focus has been on structural studies of the cementing clay component of the stone as the clay is critical to the integrity of the material. Sydney yellow block sandstones typically contain relatively large amounts of sand (60-68\%) bound together by a $16-25 \%$ clay-based matrix, with small quantities of impurities including iron-rich minerals. For this study, thermal analysis has been used to compare clays isolated from weathered and unweathered sandstones. In addition, clays samples with non-structural iron removed were also investigated in order to determine the significance of the impurities in the 
analyses. X-ray diffraction results are also reported and provide confirmation of the difference in clay structures. Sandstone removed from Sydney's St Mary's Cathedral as part of a restoration programme was investigated.

\section{Materials and methods}

\section{Materials}

Sandstone samples from St Mary's Cathedral were supplied by Gosford Quarries Pty Ltd (Australia). The samples obtained were the more extensively decayed yellow block sandstones replaced in recent years as part of restoration programmes. The weathered surfaces were separated from the unweathered cores of the decayed sandstones by use of an industrial diamond saw and small amounts of water were used as a coolant during cutting.

The clay-based material was separated from the sandstone samples because the presence of a high amount of quartz may interfere with the analysis. Both weathered and unweathered sandstones were manually crushed using a mortar and pestle and then mixed with distilled water $\left(5 \mathrm{gL}^{-1}\right)$. An ultrasonic probe with frequency of $20 \mathrm{kHz}$ and energy of 20W was used to dislodge the clay-based material from the sand particles [2-3]. The decanted clay materials were suspended in distilled water and the clay particles $\leq 2 \mu \mathrm{m}$ were collected using a gravity settling method according to Stokes' Law [4-5]. The clay particles collected by centrifugation were dried in a $50^{\circ} \mathrm{C}$ oven overnight and separated into two portions. One portion was stored in a desiccator and the second portion was further treated by $\mathrm{Na}_{2} \mathrm{~S}_{2} \mathrm{O}_{3} \cdot 5 \mathrm{H}_{2} \mathrm{O}$ and $\mathrm{NaHCO}_{3}$ to remove non-structural iron (iron impurities) from the clay samples [6]. Standard kaolinite from the Kentucky-Tennessee Clay Company (USA) was used for comparison purposes.

\section{Thermal analysis}

A Setaram Setsys 16/18 TG-DSC 15 Thermal Gravimetric Analysis instrument was used for the TGA and DSC analysis of the clay samples. Approximately $10 \mathrm{mg}$ of clay was placed in a platinum crucible and analysed in atmospheric air from room temperature up to $1200^{\circ} \mathrm{C}$ at a heating rate of $1^{\circ} \mathrm{C} \mathrm{min}^{-1}$. A temperature calibration was carried out with indium, tin, zinc, antimony, gold and silver. The buoyancy of the furnace was corrected by measuring a baseline using a point to point correction. Standard kaolinite was analysed for comparison purposes. Triplicate analyses were performed for each sample. 


\section{$X$-ray diffraction}

XRD patterns of the powder mounts of standard kaolinite and both weathered and unweathered cementing clay samples were recorded with a Siemens D5000 X-ray diffractometer. A Phillips PW2276/20 X-ray tube was used at a power of $40 \mathrm{~mA}$ and $40 \mathrm{kV}$ to produce $\mathrm{CuK} \alpha$ radiation. The instrument was configured to scan over a range of $2 \theta=3^{\circ}$ $30^{\circ}$ at a rate of $0.020^{\circ} 2 \theta$ per second. The heating rate for the hot stage XRD was $1^{\circ} \mathrm{s}^{-1}$ over a temperature range of $25^{\circ} \mathrm{C}$ to $750^{\circ} \mathrm{C}$. Triplicate analyses were performed on each sample.

\section{Results and discussion}

\section{Thermal analysis}

TGA and DSC analysis was carried out on weathered and unweathered clays before and after non-structural iron removal, as well as on a sample of standard kaolinite and the results are illustrated in Figures 1 and 2 . The mass loss observed in the region $30-130^{\circ} \mathrm{C}$ in each of the DTG curves indicates the dehydration of the clay. The dehydration of kaolinite is also observed in the DSC traces with an endothermic peak observed between $30^{\circ} \mathrm{C}$ to $130^{\circ} \mathrm{C}$ in each case. The process is associated with adsorbed non-structural moisture being driven out of the clay particles.

Peaks in the range $200-400^{\circ} \mathrm{C}$ for all samples indicate the dehydration of iron oxyhydroxide, $\mathrm{FeO}(\mathrm{OH})_{x}$, and the crystallisation of iron oxide, $\mathrm{Fe}_{2} \mathrm{O}_{3}$ [7-8]. The larger peaks observed in the weathered clay confirm that there are higher concentrations of iron impurities present in these samples. The leaching and oxidation of the detected iron impurities provides a source of iron for $\mathrm{Fe}^{3+}$ substitution for $\mathrm{Al}^{3+}$ and/or $\mathrm{Si}^{4+}$ in the kaolinite structure [1,9-10].

A dehydroxylation process is observed in the thermal data in the range $450-750^{\circ} \mathrm{C}$ and structural water is lost in this process. Hydroxyl groups in the clay structure are lost as water. During this process the structure of the kaolin clay breaks down to form water and metakaolin, which is a degradation product of kaolin clay with no binding power [11]. In this region in each of the DTG curves, a doublet with peaks centred at $580^{\circ} \mathrm{C}$ and $680^{\circ} \mathrm{C}$ is observed. The peak centred at $580^{\circ} \mathrm{C}$ corresponds to the dehydroxylation of kaolinite [12]. The second peak at $650^{\circ} \mathrm{C}$ is likely to correspond to a more thermally stable more ordered polymorph of kaolinite, dickite. This peak is present in both weathered and unweathered sandstones. The doublet is retained upon non-structural iron removal in both weathered and unweathered samples. 
A sharp peak in each of the DTG and DSC curves observed in the region $980-1030^{\circ} \mathrm{C}$ is believed to be associated with the formation of mullite [1,4,13-15]. The formation of mullite, the thermal degradation product of kaolin clay in the weathered samples, indicates that the cementing material in the weathered sandstones retains its kaolin origin. The alteration of the crystal structure through iron substitution has not reached a state of complete destruction. Mullite is also detected in both weathered and unweathered clays after nonstructural iron removal. This suggests that the clay structure is not altered by the nonstructural iron removal method, in which only the adsorbed iron impurities were dissolved without removal of the structural metals.

\section{$X R D$}

XRD hot stage analysis was performed on the weathered and unweathered cementing clay samples before and after non-structural iron removal and the data are presented in Figures 3-6. The patterns of both the weathered and unweathered clay samples at room temperature contain peaks at $2 \theta=12^{\circ}, 19.8^{\circ}, 21.3^{\circ}$ and $24.5^{\circ}$ that are due to kaolinite. The peaks at $2 \theta=12^{\circ}$ and $24.5^{\circ}$ (basal $d$ spacings of $7.15 \AA$ and $3.75 \AA$, respectively) represent the preferred orientation of the $\left(\begin{array}{lll}0 & 0 & 1\end{array}\right)$ and $\left(\begin{array}{lll}0 & 0 & 2\end{array}\right)$ planes and the sharpness of these peaks suggests that it is a relatively high crystallinity (or more ordered) clay. The peaks at $2 \theta=8.6^{\circ}$, $17.6^{\circ}, 19.5^{\circ}$ and $26.6^{\circ}$ (basal $d$ spacings of $10.3 \AA, 5.06 \AA, 4.56 \AA$ and $3.35 \AA$, respectively) represent the crystal planes of those from the mixed layer clays such as illite, muscovite and vermiculite [16-17]. The broadness of these peaks denotes less ordered (or more amorphous) crystal structures.

The peaks representing the mixed layer clays particularly, at $2 \theta=8.6^{\circ}, 17.6^{\circ}$ and $19.5^{\circ}$, show a slight increase in intensity on heating. This suggests that the mixed layer clays in the cementing material contains predominantly illite and/or muscovite, as illite and muscovite show noticeable increases in the intensities of peaks when water layers are removed upon heating. Their sheet silicate structures are usually maintained up to $750^{\circ} \mathrm{C}$ [4].

The peaks representing the kaolinite crystal planes in the unweathered clay samples before and after non-structural iron removal decrease in intensity at approximately $550^{\circ} \mathrm{C}$ and are completely destroyed at around $700^{\circ} \mathrm{C}$ (Figures 3 and 5). This result provides support for the theory of the presence of two types of kaolin clays in the cementing materials noted from the thermal analysis, where the original clay was destroyed at a temperature similar to that of the standard kaolinite. However, the second type of clay structure is not completely destroyed until around $700^{\circ} \mathrm{C}$. This type of clay shows a stronger resistance to thermal degradation 
compared to the first type of cementing clay and the standard kaolinite, where the total destruction of the crystal structure occurs at approximately $650^{\circ} \mathrm{C}$.

The XRD pattern of the weathered clay before iron removal shows a similar pattern to that of the unweathered clay. Although the kaolinite peaks start to decrease in intensity at the same temperature as the unweathered samples, the crystal structure is completely destroyed at around $650^{\circ} \mathrm{C}$. The peaks representing the mixed layer clay fraction show a similar behaviour to that of the unweathered clay samples. XRD patterns of both weathered and unweathered clay samples after non-structural iron removal show a similar trend to clay samples before iron removal, but the unweathered samples are slightly more resistant to heating.

\section{Conclusions}

TGA and DSC analysis of clays extracted from weathered and unweathered Sydney sandstone demonstrate that the clay is of the kaolin type. A polymorphic clay structure such as that of dickite was also found in the clay material, resulting in an extra peak in the dehydroxylation region. In addition, XRD patterns further confirm the origin of the cementing clay and the XRD hot stage results support the presence of a more ordered clay structure in the cementing material.

The presence of dickite provides Sydney sandstone with a more heat resistant binder. The abundant iron in the stone gives a source of iron for the isomorphous substitution where it is possible for $\mathrm{Fe}^{3+}$ to substitute for $\mathrm{Al}^{3+}$. Although substitution allows the integrity of the original stone to be retained, the crystal structure of the aluminosilicate is destabilised causing brittleness of the weathered sandstone.

\section{Acknowledgements}

The authors wish to acknowledge the support of the Heritage Group, NSW Department of Planning.

\section{References}

1. K.H. Friolo, B.H. Stuart and A. Ray, J. Cult. Her. 4 (2003) 211.

2. R. Roscoe, P. Buurman and E.J. Velthorst, Eur. J. Soil Sci., 51 (2000) 445.

3. M.W. Schmidt, C. Rumpel and I. Koqel-Knabner, Eur. J. Soil Sci., 50 (1999) 87.

4. D. Carroll, Clay Minerals: A Guide to Their X-ray Identification, The Geological Society of America, Colorado, 1970 
5. E.M. Rutledge, L.P. Wilding and M. Elfield, Proc. Soil Sci. Soc. Amer. 31 (1967) 287.

6. O.P. Mehra and M.L. Jackson ML, Clays and Clay Min., 7 (1960) 317.

7. S.V.S. Prasad and V. Sitakara Rao, V. J. Mat. Sci., 19 (1984) 3266.

8. C.L. Sharma, M. Nath and N. Bharti, N., J. Mat. Sci. Lett., 13 (1994) 1010.

9. P.L. Hall, Clay Minerals, 15 (1980) 321.

10. T. Delineau, T. Allard, J.P. Muller, O. Barres, J. Yvon and J.M. Cases, Clays and Clay Min., 42 (1994) 308.

11. W. Ryan, Properties of Ceramic Raw Materials, Pergamon Press, Oxford, 1978.

12. R.E. Grim, Clay Mineralogy, McGraw-Hill, New York, 1968.

13. K.H. Friolo, A.S. Ray, B.H. Stuart and P.S. Thomas, J. Therm. Anal. Cal. 80 (2005) 559.

14. P.S. Nicholson and R.M. Fulrath, J. Amer. Ceram. Soc., 53 (1970) 237.

15. A.K. Ismailov, Glass and Ceramics, 38 (1981) 363.

16. J.E. Gieseking, Inorganic Components, Soil Components, Springer-Verlag, New York, 1975.

17. J.B. Dixon, S.B. Weed, J.A. Kittrick, M.H. Milford and J.L.White, Minerals in Soil Environments, Soil Science Society of America, Madison, 1977. 


\section{List of figures}

Figure 1. DSC traces of (a) standard kaolinite, (b) unweathered and (c) weathered clay before non-structural iron removal and (d) unweathered and (e) weathered clay after non-structural iron removal.

Figure 2. DTG data for (a) standard kaolinite, (b) unweathered and (c) weathered clay before non-structural iron removal and (d) unweathered and (e) weathered clay after non-structural iron removal.

Figure 3. XRD patterns of the unweathered clay before non-structural iron removal.

Figure 4. XRD patterns of weathered cementing clays before non-structural iron removal.

Figure 5. XRD patterns of unweathered cementing clays after non-structural iron removal.

Figure 6. XRD patterns of weathered cementing clays after non-structural iron removal. 


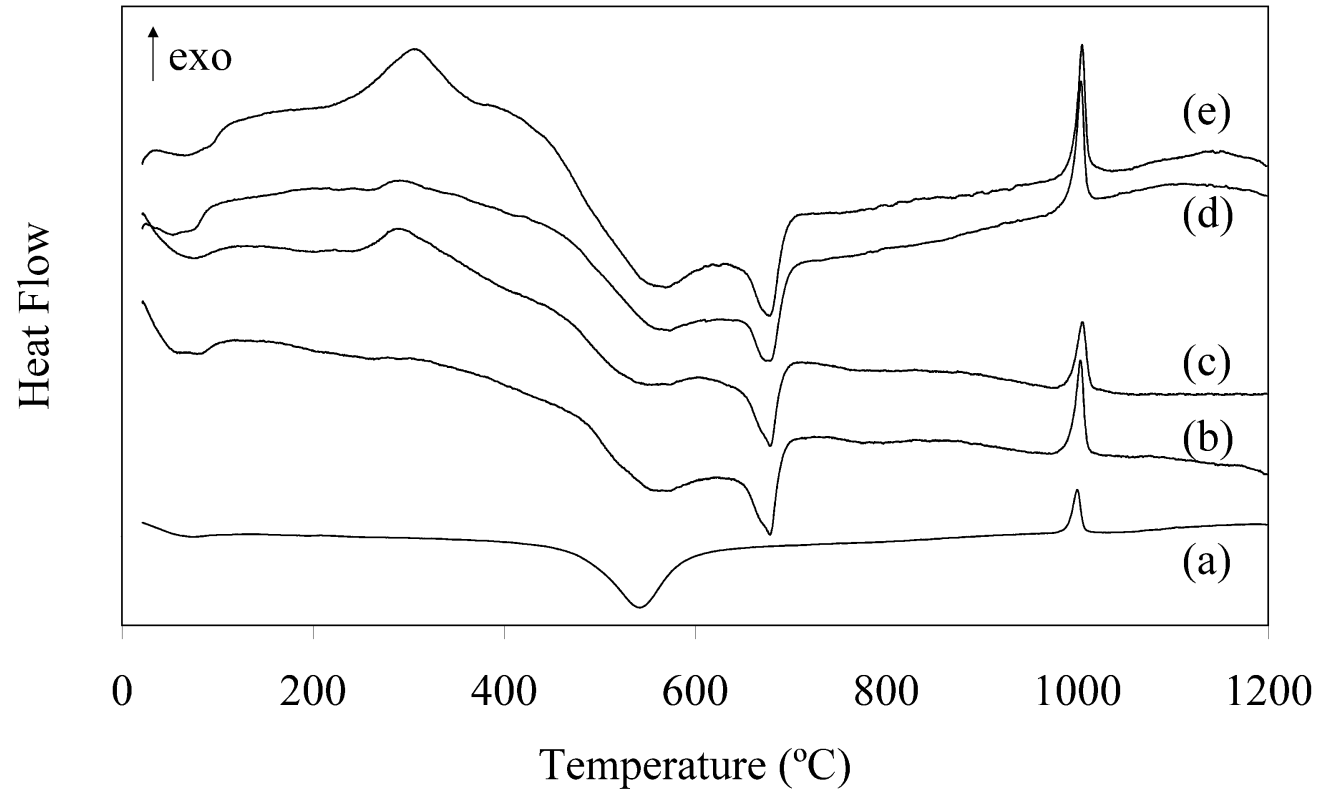




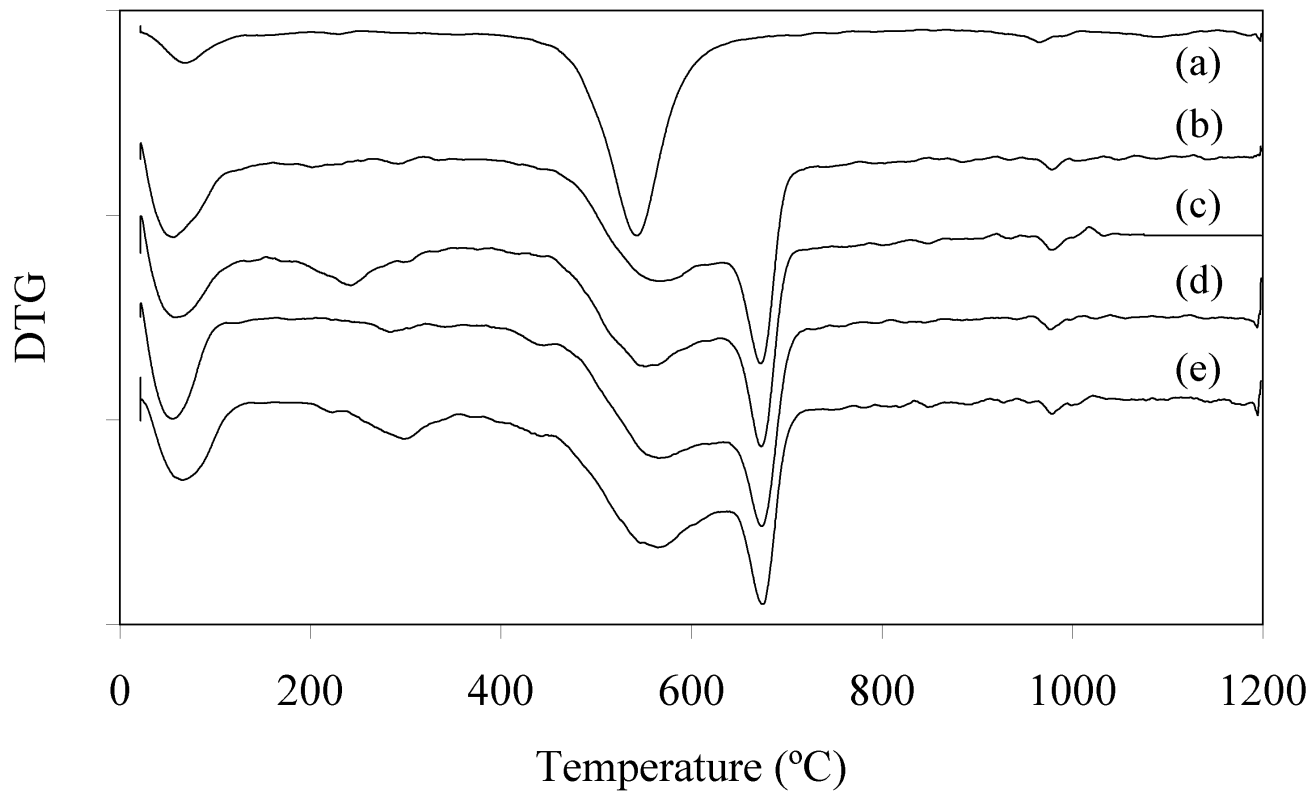




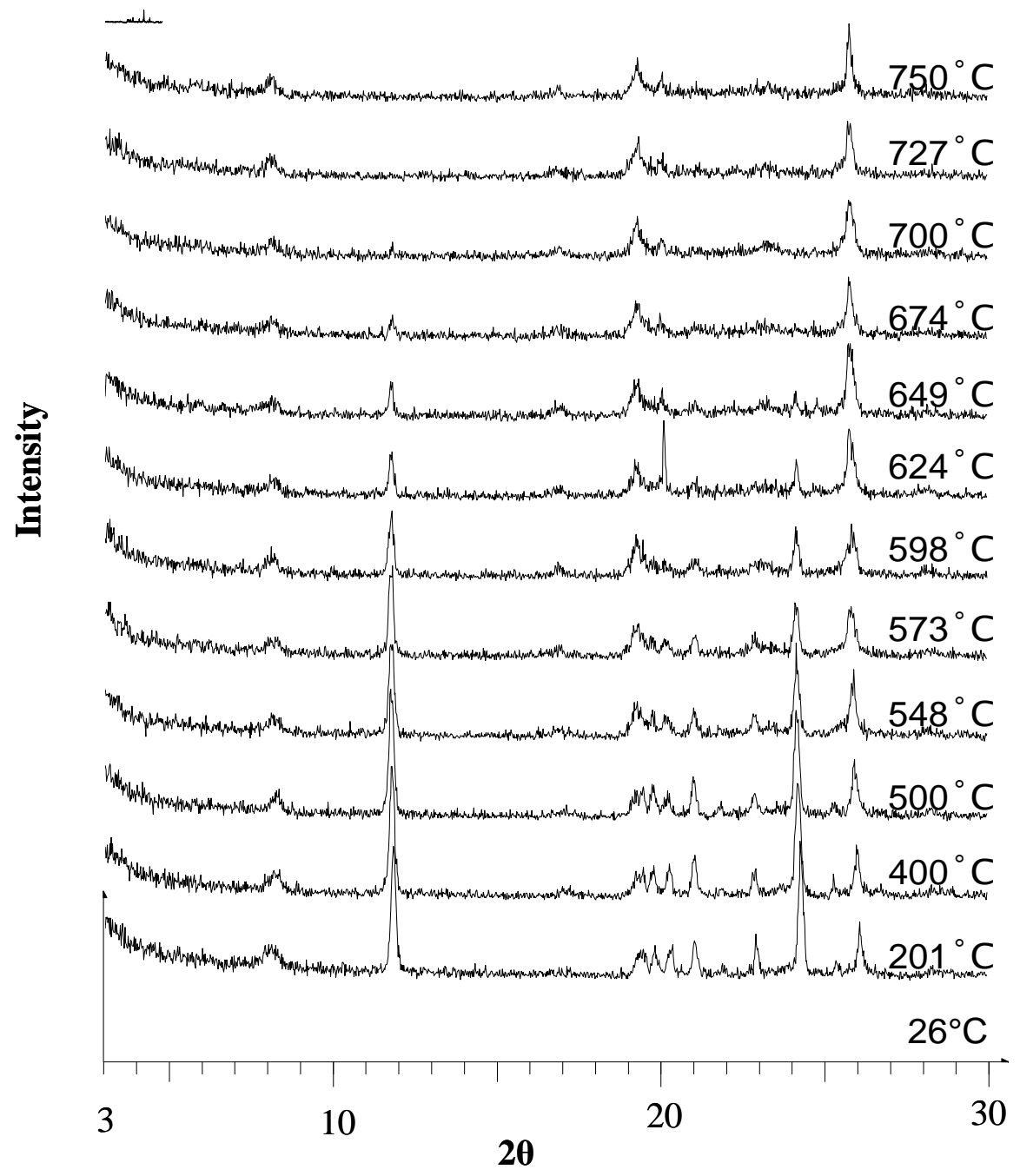




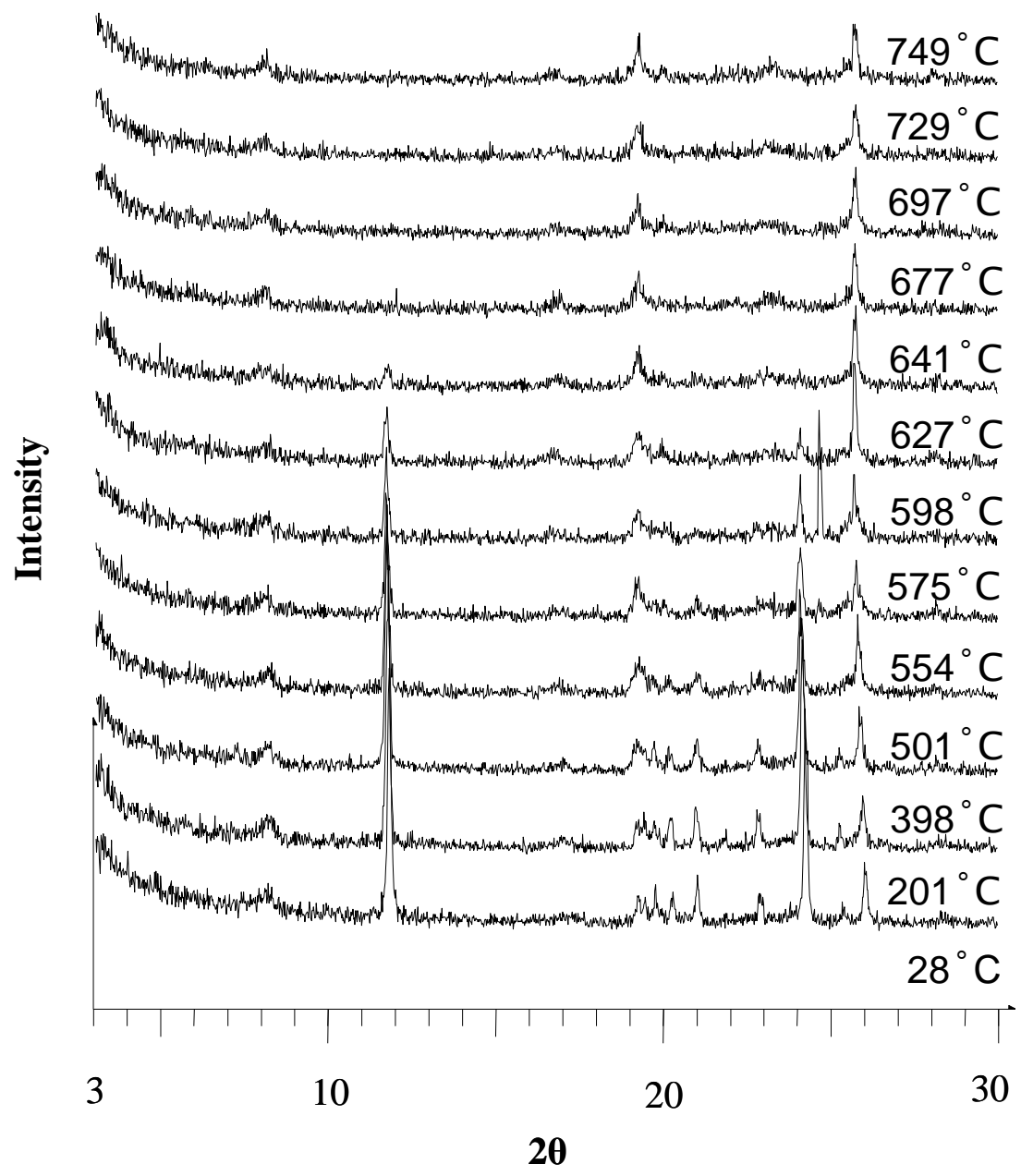




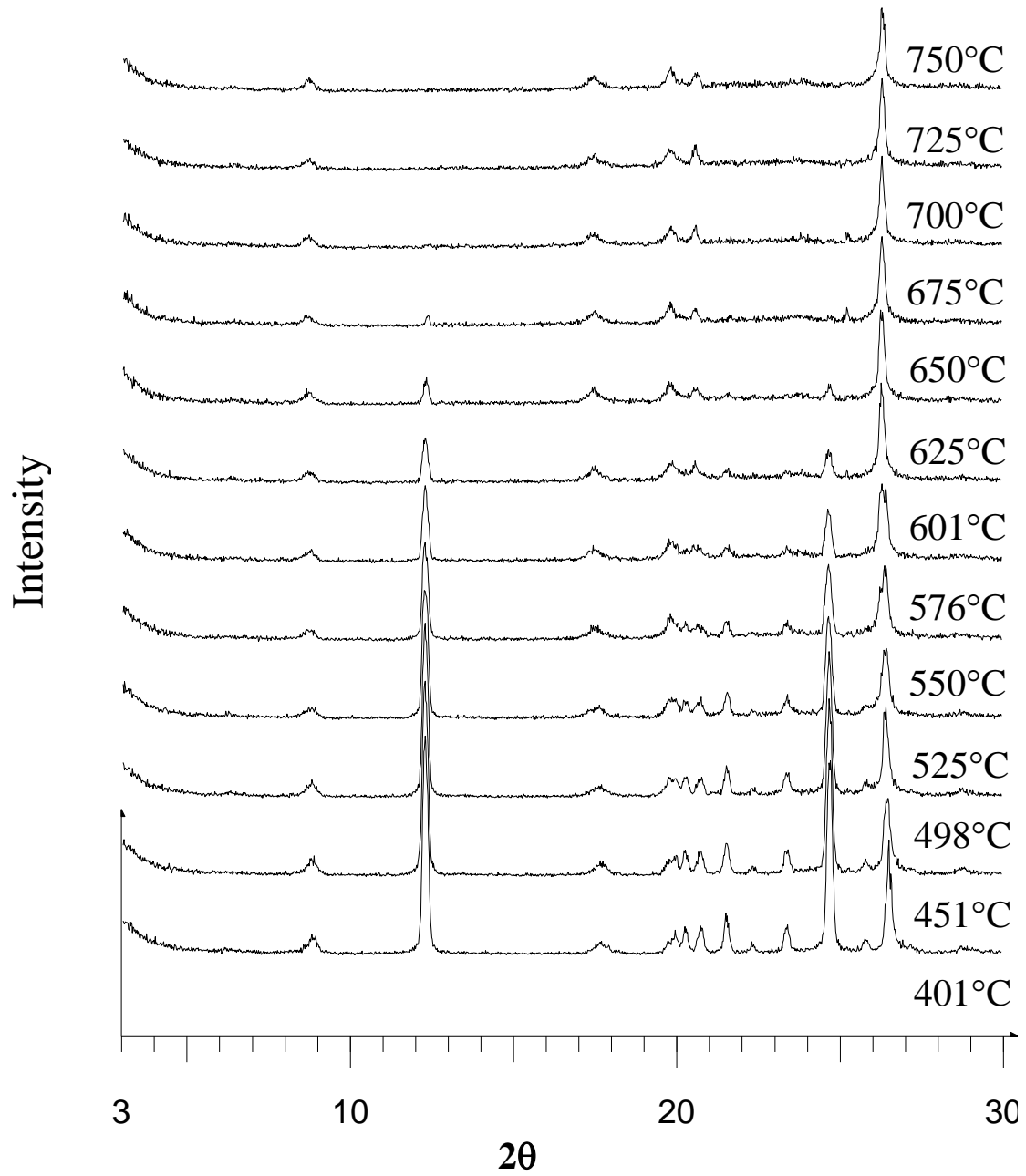




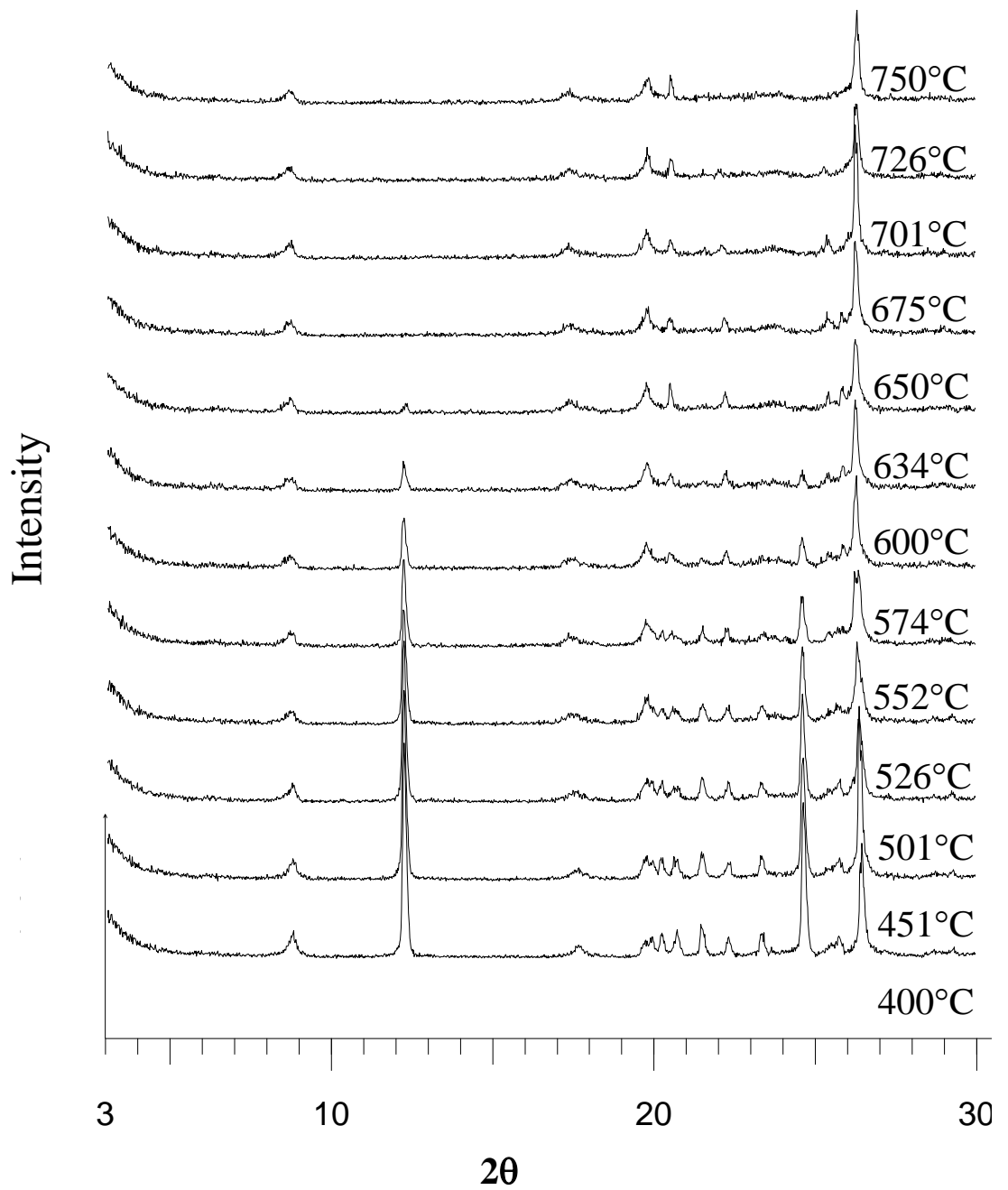

